\title{
The Effects
}

\section{of Individual Monetary Incentives}

\section{With and Without Feedback}

\author{
Barbara R. Bucklin \\ Heather M. McGee \\ Alyce M. Dickinson
}

\begin{abstract}
This study examined the effects of an individual monetary incentive system with and without feedback to determine if feedback would supplement the effects of incentives. Participants were seven college students who performed a computerized task called SYNWORK. SYNWORK presented four sub-tasks concurrently: memory, arithmetic, visual monitoring and auditory monitoring. Participants earned points for correct responses. The dependent variable was the number of points earned. $\mathrm{An} \mathrm{ABAC}$ design was used with $\mathrm{A}=$ individual monetary incentives without feedback, $\mathrm{B}=$ individual monetary incentives with feed-
\end{abstract}

Barbara R. Bucklin is affiliated with Ardent Learning, Irvine, CA. Heather M. McGee and Alyce M. Dickinson are affiliated with Western Michigan University.

Address correspondence to: Alyce M. Dickinson, Department of Psychology, Western Michigan University, Kalamazoo, MI 49008-5439 (E-mail: alyce.dickinson@ wmich.edu).

The authors want to thank Jack Michael, John Austin, and Robert Brinkerhoff for their contributions to the development and analysis of the study. They also want to thank Tim Elsmore for providing the SYNWORK task and reprogramming it to meet our research needs.

This research was funded by grants from the Organizational Behavior Management Network, Western Michigan University's Graduate College Research Fund, an Aubrey Daniels International. The authors want to express their gratitude, in particular, to Dr. Aubrey Daniels for his generosity.

This study was conducted in partial fulfillment of the requirements for the doctora degree of the first author.

Journal of Organizational Behavior Management, Vol. 23(2/3) 2003 http://www.haworthpress.com/web/JOBM

C 2003 by The Haworth Press, Inc. All rights reserved.
Digital Object Identifier: $10.1300 / \mathrm{J} 075 \mathrm{v} 23 \mathrm{n} 02 \_05$ 
back, and C = hourly pay with feedback. Sessions were 90 minutes, and there were 5 to 10 sessions per phase. The point scores of six of the seven participants increased when feedback was added to the incentive system but stabilized or continued to increase when feedback was removed. The feedback intervention was staggered in time across participants, and performance increased when feedback was added, hence the data suggest that feedback enhanced the effects of the incentives. One possible reason for the reversal failure is that feedback evoked higher levels of performance that were then maintained by the additional incentives. Because performance did not reverse, however, the results must be viewed cautiously. [Article copies available for a fee from The Haworth Document Delivery Service: 1-800-HAWORTH. E-mail address: <docdelivery@ haworthpress. com> Website: <http://www.HaworthPress.com> () 2003 by The Haworth Press, Inc. All rights reserved.]

KEYWORDS. Incentives, hourly pay, feedback, laboratory, organizational behavior management

Individual monetary incentive systems, typically with feedback as a component have been researched in both laboratory and applied settings, and have resulted in appreciably higher levels of performance than hourly pay (e.g., Frisch \& Dickinson, 1990; Gaetani, Hoxeng, \& Austin, 1985; George \& Hopkins, 1989; LaMere, Dickinson, Henry, Henry, \& Poling, 1996; London \& Oldham, 1977; Pritchard, Hollenback \& DeLeo, 1980; Riedel, Nebecker \& Cooper, 1988; Smoot \& Duncan, 1997; Wagner \& Bailey, 1997). Statistical meta-analyses have also confirmed the effectiveness of individual monetary incentive systems (Jenkins, Gupta, Mitra, \& Shaw, 1998) and, more generally, tangible work incentives (Stolovich, Clark, \& Condly, 2002).

Although relatively few in number, some studies have compared different types of individual monetary incentive systems in an attempt to identify the most effective performance-pay arrangements. These studies have generally found performance to be comparable under the various arrangements (Bucklin \& Dickinson, 2001). For example, a series of studies conducted in the late 1970s and early 1980s compared various fixed and variable ratio schedules of incentive delivery (i.e., Fixed-Ratio 1, Fixed-Ratio 3, Variable-Ratio 2, Variable-Ratio 3, Variable-Ratio 4) (Berger, Cummings, \& Heneman, 1975; Latham \& Dossett, 1978; Pritchard et al., 1980; Pritchard, Leonard, Von Bergen, \& Kirk, 1976; Saari \& 
Latham, 1982; Yukl \& Latham, 1975; Yukl, Latham, \& Pursell, 1976; Yukl, Wexley, \& Seymore, 1972). Results were too ambiguous to conclude that different ratio schedules resulted in performance differences (Bucklin \& Dickinson, 2001; Dickinson \& Poling, 1996). Hantula (2001) arrived at the same conclusion when he reviewed the effects of different schedules of reinforcement on organizational behavior. Moreover, his review included studies that examined both monetary and nonmonetary consequences.

Two studies compared the effects of linear, accelerating, and decelerating piece-rate pay on performance (Oah \& Dickinson, 1992; Smoot \& Duncan, 1997). With linear piece-rate pay, the amount earned per piece remains constant regardless of how many "pieces" or work units the performer completes. With accelerating piece-rate pay, the amount earned per piece increases as the performer completes more pieces. With decelerating pay, the per piece incentive decreases as the performer completes more pieces. As with the studies that examined the schedule of incentive delivery, the results of these two studies were mixed (Bucklin \& Dickinson, 2001; Duncan \& Smoot, 2001).

Another series of studies examined whether the percentage of base pay and total pay earned in incentive pay influenced performance (Dickinson \& Gillette, 1993; Frisch \& Dickinson, 1990; LaMere et al., 1996; Matthews \& Dickinson, 2000; Riedel et al., 1988). In these studies, participants could earn from $0 \%$ to $100 \%$ of their total pay or base pay in incentives. Researchers reasoned that higher percentages of incentives should result in higher levels of performance because a greater proportion of total pay is based on the actual performance of the worker, and hence, the incentives should compete more effectively with rewards derived from off-task activities. In all of the studies, however, as long as the percentage of incentive pay to base pay and total pay was greater than zero (that is, the individuals earned incentive pay), different percentages of base pay and total pay earned in incentive pay resulted in comparable performance (Dickinson \& Gillette, 1993; Frisch \& Dickinson, 1990; LaMere et al., 1996; Matthews \& Dickinson, 2000; Riedel et al., 1988). The incentive percentages examined have ranged from $3 \%$ to $100 \%$ of a person's base pay and total pay. For a more comprehensive review of the above studies as well as studies that examined different ratio schedules of delivery and different per-piece incentive arrangements, we recommend that readers refer to Bucklin and Dickinson (2001).

One analysis, suggested by Mawhinney (1982), predicts that performance would be similar under various performance-pay arrangements, 
given certain conditions. If money is more reinforcing than consequences derived from other tasks and delivered on a competitive schedule, individuals would be expected to perform the incented tasks at high rates in order to maximize their earnings, and hence their overall rate of reinforcement. This would be particularly likely to occur if individuals were capable of formally analyzing the contingencies, given their complexity, and developed verbal rules that enabled maximization. If the preceding conditions existed, performance would be high regardless of the particular ratio schedule, proportion of total pay or base pay earned in incentive pay, or the amount of the per piece incentive, particularly if the alternative sources of reinforcement were weak. Results from a demonstration study by Mawhinney (1982) provide support for his analysis, not only for the maximization of reinforcement, but also for the formal analysis of contingencies and the development of verbal rules.

Three additional factors have been proposed as potentially contributing to the results of the studies: the delivery of frequent performance feedback (Bucklin \& Dickinson, 2001; C. Hyten, personal communication, January, 1993; Matthews \& Dickinson, 2000); and, in the case of the laboratory simulations, the lack of attractive alternative activities (Matthews \& Dickinson, 2000; T. C. Mawhinney, personal communication, January, 1993), and social demands related to the presence of the experimenter (Matthews \& Dickinson, 2000). In most of the studies, performance feedback was a planned component of the incentive system or readily available due to the nature of the task (Bucklin \& Dickinson, 2001). This feedback typically consisted of specific, daily information about individual performance and how that performance related to the incentive earned. Such feedback may sustain performance under different incentive arrangements. In other words, feedback may eliminate any performance differences that would result from different incentive pay arrangements if it were not present. Within the context of Mawhinney's (1982) analysis, frequent feedback might make it more likely that individuals would formally analyze the contingencies and develop verbal rules that would successfully lead to maximization of reinforcement.

In addition to explaining findings from previous studies, the answer to the question of whether feedback enhances the effects of monetary incentives is important in its own right. Buyniski (1995) reported that many organizations do not provide feedback to employees when they pay them incentives. If feedback does enhance performance, then orga- 
nizations could improve employee productivity by implementing feedback systems along with incentive pay.

The presence of feedback in studies of different performance-pay arrangements emerged as a major methodological issue in the review conducted by Bucklin and Dickinson (2001). They determined that any conclusions drawn from the studies of different ratio schedules of delivery, percentages of incentive pay to total pay and base pay, and the amount of the per piece incentives should be restricted to situations where individual monetary incentives are combined with frequent feedback; thus, they proposed that it was important to isolate the effects of monetary incentives from those of feedback.

Two studies have examined the effects of monetary incentives with and without feedback on performance, however, both contained methodological confounds that made interpretations problematic (Agnew, Dickinson, Acker, Cronin, \& Goldwater, 1992; Smoot \& Duncan, 1997). The main purpose of the current study was to examine the effects of monetary incentives with and without feedback on performance, while controlling the other two variables that have been identified as potential confounds in laboratory studies, the lack of attractive alternative activities and social demands. The primary performance measure included a quality criterion; that is, the main dependent variable consisted of "correct" responses. However, the quality of performance (percentage of correct responses) was assessed separately to determine whether any potential increases in performance would be accompanied by decreases in quality. The latter assessment was included to address the long-standing concern that there are trade-offs between quantity and quality (Adam, 1972; Fitts, 1966). If quality suffers when quantity increases, any benefits to organizations from increased rates could be offset by waste and scrap.

\section{FEEDBACK}

Performance feedback (i.e., information about past performance) has been the most common intervention in Organizational Behavior Management (OBM). Approximately $65 \%$ to $70 \%$ of OBM interventions have used feedback alone or in combination with other interventions, and this figure has remained relatively constant over the years (Balcazar, Shupert, Daniels, Mawhinney, \& Hopkins, 1989; Bucklin, Alvero, Dickinson, Austin, \& Jackson, 2000; Nolan, Jarema, \& Austin, 1999). In their classic review, Balcazar et al. (1985/86) found that feedback, 
when used alone, consistently improved performance in $28 \%$ of the articles reviewed. It had mixed effects in 57\% of the articles, and no effects in $15 \%$. Combinations of feedback with other consequences of performance-related behaviors were more effective: Effects were consistent in $52 \%$ of the articles and mixed in $42 \%$. Performance was not affected in only $6 \%$ of the articles. When tangible rewards, such as money, food and gasoline were combined with feedback, performance improved in 13 out of 15 applications. They concluded:

An analysis of the ways in which feedback might operate and consideration of the basic research suggest that it will be effective to the extent that it is related to functional, differential reinforcement. (p. 65)

Similarly, Alvero et al. (2001) found that feedback combined with consequences produced more consistent effects than feedback alone, although the differences were not as great. They reported that feedback alone had consistent effects in $47 \%$ of the articles while feedback with behavioral consequences, feedback with antecedents and behavioral consequences, and feedback with goal setting and behavioral consequences had consistent effects in 58\%, 67\%, and 67\% of the articles, respectively.

Consistent with the preceding analyses, studies have shown that monetary incentives enhance the effectiveness of feedback. To conduct the assessment, feedback has been implemented prior to combining it with individual monetary incentives. For example, Gaetani et al. (1985), using an ABAC design, implemented feedback as the B condition, and feedback with commission compensation as the $\mathrm{C}$ condition. The participants were two machinists. During baseline (the A condition), the owner of the business measured the daily dollar amount charged to customers but did not show these data to the machinists. When machinists self-recorded their performance during the feedback phase, performance approximately doubled. When a 5\% commission was added, performance increased again, and was markedly higher than during the feedback phase. Similarly, Dierks and McNally (1987) reported performance improvements when feedback was provided to proof operators at a bank, and additional improvements when incentives were added to the feedback. These examples demonstrate the effectiveness of feedback and the supplemental effects of monetary incentives. They do not, however, assess whether feedback enhances the effectiveness of the incen- 
tives. Such an assessment requires that incentives be implemented with and without feedback.

Balcazar et al. (1985/86) and others (e.g., Duncan \& Bruwelheide, 1985/86; Fairbank \& Prue, 1982; Peterson, 1982) discussed the possibility that feedback might enhance the effectiveness of behavioral consequences, and identified the potential behavioral mechanisms that may cause feedback to have such an effect. For example, when feedback is delivered along with a consequence, it may function as a discriminative stimulus to prompt performance. Due to its presentation with other reinforcers, it may also become a conditioned reinforcer. Balcazar et al. specifically addressed how feedback could enhance the effectiveness of incentive pay, stating that feedback may prompt higher levels of performance because similar kinds of feedback have been correlated with reinforcement or punishment in the past. The elevated performance levels are then reinforced and maintained by additional incentive pay, which in turn, maintains the feedback as a discriminative stimulus and perhaps as a conditioned reinforcer as well. In addition to considering discriminative and reinforcing effects of feedback, Duncan and Bruwelheide (1985/86) and Peterson (1982) suggested that it may function as an establishing operation (Michael, 1982), increasing the reinforcing value of the worker's accomplishment and evoking work performance that produces that accomplishment.

Several authors (e.g., Agnew et al., 1992; Agnew \& Redmon, 1992; Peterson, 1982) maintained that feedback, as it is typically delivered in work settings, violates the definitions of discriminative stimuli and reinforcing stimuli, primarily due to the temporal delay between the presentation of the feedback and the behavior or, in the case of reinforcing stimuli, between the behavior and the feedback. Therefore, these authors suggested that feedback might influence work performance primarily through rule control.

The precise mechanisms through which feedback improves performance are usually unknown, and no doubt differ depending upon the situation and the performer's history. Nonetheless, as indicated above, several explanations suggest that feedback may augment the effectiveness of behavioral consequences.

Prior to well-controlled attempts to examine the augmentative effects of feedback, Parsons $(1974,1978,1992)$ reanalyzed data from the famous Hawthorne studies and concluded that feedback enhanced the performance of relay assemblers who were paid small group monetary incentives. Initially, the relay assemblers were paid group monetary incentives that were based on the performance of $100+$ workers. In the 
first study conducted in the Relay Assembly Test Room, five assemblers were switched from the large group monetary incentives to small group incentives with feedback. The small group incentives were based on the performance of only the five participants. Assemblers received immediate feedback on their own performance and daily feedback on the total group's performance. When the small group incentives and feedback were implemented, performance increased immediately, and continued to rise for the next two years: "Although the method of calculation was not indicated, it has been stated that the average rate for the group rose 30 percent during the first 13 [experimental] periods" (Parsons, 1974, p. 925). In a second study, another five assemblers were switched from the large group monetary incentives to small group incentives. Performance feedback was not, however, provided along with the incentives. While the performance of the second group of assemblers increased by an average of 12 percent, it stabilized at that level. Based on a detailed analysis of the data from the two studies, Parsons argued that the increasing performance trends and higher levels of performance in the first study were due to the feedback those assemblers received.

Two more recent studies examined the effects of incentives with and without feedback, but both were flawed, rendering interpretations problematic. In the first of these, Agnew et al (1992) used a within-subject ABA design to assess performance under (A) monetary incentives only and (B) monetary incentives with performance feedback. Participants were four adult females hired through a help-wanted advertisement to perform a computerized data entry task for seven hours a day for four to five weeks. The monetary incentive system included a guaranteed hourly wage and $\$ 0.57$ per entry past a proficiency level. During feedback phases, the computer displayed the number of items entered after the second and the seventh hour and, at the end of each session, the researcher graphed the total number of items completed. The introduction of feedback resulted in inconsistent effects, with only slight performance improvements for two of the four participants. However, methodological flaws make it necessary to interpret these results cautiously. For example, the monetary incentives did not appear to control the performance of two of the four performers who failed to earn incentives several times during the incentive only phases. The authors suggested that the criterion might have been too high, making it difficult for participants to earn incentives. In addition, participants reported that the task was boring and that the sessions were too long. The authors advised that 
future research be done to determine whether their inconclusive results were due to these methodological problems.

In one of four experiments designed to examine performance under linear piece-rate pay, accelerating piece-rate pay, decelerating piece-rate pay, and base pay only, Smoot and Duncan (1997) compared the effects of the three incentive pay systems with and without performance feedback. Participants were 30 college students randomly assigned to six groups. Within-subject and between-group comparisons were made. All participants were first exposed to a baseline condition consisting of base pay. Following baseline, two groups were exposed to linear piece-rate pay. Following baseline, two groups were exposed to linear piece-rate with feedback, and two groups were exposed to decelerating piece-rate pay with feedback. As the final phase for one of the two groups exposed to each of the incentive systems (i.e., three of the six groups), feedback was removed to examine its supplemental effects. Performance improved when the feedback was removed, indicating that the feedback proved when the feedback was removed, indicating that the feedback
did not provide any supplemental control. In fact, in this study, feedback had a negative effect on performance. Smoot and Duncan offered two possible explanations for these results. First, the feedback required the participant to physically check off the number of parts produced. When this feedback activity was removed, more of the session time was available for participants to perform the task. Given that sessions were only 15 minutes, the additional production time could well account for the increased performance. Second, the effects of feedback in the previous condition may have carried over to the incentive without feedback condition. In other words, the effects of feedback may not have been removed because the feedback condition preceded the no feedback condition. Due to these two confounds, results relating to the supplemental effects of feedback on incentive systems are not conclusive.

\section{ALTERNATIVE ACTIVITIES AND SOCIAL DEMANDS}

Most of the studies that have compared the effects of different types of individual monetary incentive systems have been conducted in the laboratory. For example, of the studies that examined the effects of various percentages of incentive pay to base pay and total pay, LaMere et al. (1996) was the only one conducted in an actual work setting. As stated earlier, researchers and critics have proposed that the failure to find performance differences under the various incentive arrangements may have been due not only to feedback but also to the lack of attractive alternative activities and to social demands related to the presence of the 
experimenter. These potential confounds relate to differences between actual work settings and laboratory simulations. Work settings offer a vast array of attractive off-task activities that compete, often effectively, with work tasks and the effects of incentives. Although off-task activities were available to participants in all of the laboratory studies, they may not have been as attractive as those in a work setting. Without attractive alternatives, participants may spend all of their time engaging in the experimental task regardless of the specific arrangement between the incentives and performance. Over the years, Mawhinney (1975 1984) (Mawhinney \& Mawhinney, 1982) has repeatedly addressed this issue, urging organizational managers and researchers to recognize that individuals are likely to maximize their performance under a particular schedule of reinforcement if alternative sources of reinforcement are weak. In addition, in actual work settings, performers have the opportunity to engage in off-task activities when the supervisor is not present, thereby avoiding potential reprimand. The presence of the experimenter in the laboratory studies may have unrealistically restricted the extent to which the participants engaged in off-task activities. In their investigation of the percentage of incentive pay to total pay, Matthews and Dickinson (2000) attempted to eliminate both of the aforementioned problems by using alternative activities that were highly attractive to participants (computer games) and by arranging for the researcher to remain out of the experimental room throughout the session. The manipulations appeared to be successful, as all participants spent some amount of time playing the computer games. Participants who received incentive pay, however, spent significantly more time working than those who received hourly pay. Akin to the results of other studies of incenwho received hourly pay. Akin to the results of other studies of incen-
tive percentages, participants who received $10 \%$ of their total pay in incentive pay spent the same amount of time working as those who received $100 \%$ of their total pay in incentive pay. Even though participants who were paid incentives spent more time working than participants who were paid hourly, their task performance (the number of computer screens completed correctly) did not differ from those who were paid hourly. Matthews and Dickinson attributed these latter results to the type of experimental task used, and recommended that additional research be conducted with different experimental tasks.

\section{PURPOSE OF THE STUDY}

To summarize, when parameters of individual monetary incentive systems have been altered, performance has generally been compara- 
ble. The delivery of frequent feedback is one factor that may account for the equivalent performance levels. If feedback enhances the effectiveness of individual monetary incentives, then it could sustain performance under the various parameters, eliminating differences that might otherwise occur. Although the augmentative effects of feedback are supported by conceptual analyses, the results of studies that have examined the effects of individual incentives on performance with and without feedback have been inconclusive. Two additional factors, arising from the fact that most of the relevant studies have been conducted in laboratory settings, have been identified as possibly contributing to the performance equivalencies: the lack of attractive off-task activities and the social demands associated with the presence of the experimenter. The purpose of the present study, which was conducted in a laboratory setting, was to examine whether feedback enhances the effectiveness of individual monetary incentives while controlling for the lack of attractive alternative tasks and the social demands related to the presence of the experimenter.

\section{METHOD}

\section{Participants}

Participants were five female and two male undergraduate students recruited from junior and senior level classes at a midwestern university. Participants ranged in age from 19-24 years. They were selected based on their availability during the study, a minimum level of computational skill, financial need, and reported time spent using e-mail, internet, or computer games. Participants had to be available for at least three 90-min sessions per week, pass a computational quiz consisting of 20 addition problems taken from the experimental task at $100 \%$ accuracy, report that they planned to spend the money they earned on living expenses, and indicate that they played computer games and/or accessed e-mail or the Internet more than one hour per week. They were paid for participation as described in the Independent Variables section.

\section{Setting and Apparatus}

The study was conducted in a campus computer laboratory that contained 16 computers, with Pentium processors, arranged in four rows. Each participant had a work area that consisted of a work-task computer 
terminal, headphones, a keyboard and a mouse, and an adjacent breaktask computer terminal, keyboard and mouse.

Work task. The computer work task was SYNWORK, a synthetic work environment designed to assess complex performance (Elsmore, 1994; Elsmore, Naitoh, \& Linnville 1992). The SYNWORK program presented four sub-tasks concurrently, one in each quadrant of the computer screen: a memory task, an arithmetic task, a visual monitoring task, and an auditory monitoring task. The sub-tasks were selected for this program because they required simultaneous attention to tasks that are similar to those required for many jobs (Elsmore, 1994). Participants used the computer mouse to respond, earning points for correct responses and losing points for incorrect responses on the four sub-tasks. Points were not deducted for non-responding, however, as that would have discouraged participants from engaging in alternative activities. Points for each sub-task were added together for a total point score.

The memory sub-task was located in the upper left window of the screen. A set of six letters was randomly chosen from the alphabet and appeared in a white box at the top of the screen for the first 5 seconds of the session. After 5 seconds, the letters were replaced by a message that read "Retrieve List." The list of letters could be retrieved for an additional 5 seconds by using the mouse to click anywhere in that box, however, participants lost 10 points for each additional list retrieval. After every 20 seconds, a sample letter appeared in a box directly under the display box, and the participants had the opportunity to click the "Yes" or the "No" box at the bottom of the window. Ten points were awarded for a correct response. If participants responded incorrectly, 10 points were deducted. If participants did not respond in 20 seconds, another sample letter was displayed.

The addition sub-task, located in the upper right window of the screen, consisted of computational problems that required the addition of two randomly selected three-digit numbers. The answer was initially set at 0000. Boxes with "+" and "-" were located directly under each zero. Each mouse click on the "+" box increased the answer by one, and each click on the "-" box decreased the answer by one. A mouse click on the "Done" box at the bottom of the screen completed the problem, and presented the next problem. There were no time limits for completion of this task. Five points were awarded for correct answers, and five points were deducted for incorrect ones.

A visual monitoring sub-task was located in the lower left window of the computer screen. A pointer moved at a steady rate of 5 pixels/s toward either end of a line that was 201 pixels in length. The participants were required to click a box labeled "Reset" directly above the line to 
reset the pointer to the center. The closer the pointer was to the end of the line at the time it was reset, the more points were earned. No points were earned for clicking "Reset" when the pointer was in the middle of the line. Participants could earn from 1 to 10 points, depending upon where the pointer was when it was reset.

An auditory sub-task was located in the lower right window of the screen. A tone was presented through the headphones every 5 seconds. The tone was either low frequency $(1046 \mathrm{~Hz})$ or high frequency $(1319$ $\mathrm{Hz}$ ). Points were earned when participants clicked on the box labeled "High Sound Report" following a high frequency tone, prior to the next tone. Incorrect responses consisted of clicking the box after a low frequency tone or failing to click the box after a high frequency tone. Ten points were awarded for each correct response and 10 points were deducted for each incorrect response.

Alternative activities. During all sessions, participants had access to a computer next to their "work" computer. This computer provided alternative activities: access to e-mail and the Internet, and three computer games (Solitaire, Yatetris, and Bago). The games were selected because of their popularity as determined by a survey conducted with 468 male and female college students (Matthews \& Dickinson, 2000).

\section{Dependent Variables}

Dependent variables were the total number of points earned per session and the percentage of correct responses per session on SYNWORK. SYNWORK (Elsmore, 1994) automatically recorded these data.

\section{Independent Variables}

Participants were exposed to each of three conditions: individual monetary incentives without end-of-session feedback, individual monetary incentives with end-of-session feedback, and hourly pay with end-of-session feedback.

Individual monetary incentives without end-of-session feedback. Participants received a piece-rate pay of $\$ .10$ for every 100 points earned on SYNWORK. If participants accumulated 7,500 points per session, they received $\$ 7.50$, which was the same amount they received in the hourly-pay condition. This equivalency was based on the performance of participants in a prior study conducted with SYNWORK (Honeywell, McGee, Culig, \& Dickinson, 2002); 7,500 points was the average performance of those individuals when they were paid incen- 
tives. If participants earned more points per session, they received more money due to the piece-rate incentives. Participants were not told the number of points they earned during the sessions.

Individual monetary incentives with end-of-session feedback. The pay contingencies were identical to the pay contingencies described in the preceding section. However, in this condition, the computer displayed the number of points earned by participants at the end of each session. No feedback was provided during the session.

Hourly pay with end-of-session feedback. In the hourly-pay condition, participants received $\$ 5.00$ per hour ( $\$ 7.50$ for a 90 -min session) if they earned a minimum of 4,000 points. In work settings, employees must perform at minimum levels to avoid being fired. Thus, the purpose of the minimum standard requirement was to simulate that contingency. The 4,000-point minimum was based on previous research with SYNWORK (Honeywell et al., 2002) and represents approximately $50 \%$ of the total number of points earned by participants in that study when they were paid an hourly wage. Thus, this minimum was easy to achieve. As during the individual monetary incentive with end-of-session feedback condition, the total number of points earned during the session was displayed on the computer screen at the end of the session. No feedback was provided during the session.

\section{Experimental Design}

A within-subject ABAC experimental design was used. "A" consisted of the monetary incentive without feedback condition, "B" consisted of the monetary incentive with end-of-session performance feedback condition, and "C" consisted of the hourly pay with end-of-session feedback condition. Experimental sessions were 90-min, and there was a minimum of five sessions per phase. If performance was not stable after five sessions, participants continued in that phase until performance was stable or they had completed 10 sessions. Performance was considered stable when the number of points earned fell within a range of 750 points for three consecutive sessions. This criterion was based on visual analyses of data from previous research with SYNWORK (Honeywell et al., 2002).

\section{Procedures}

Training sessions. Before the study began, two 90-min training sessions were held to expose participants to SYNWORK and the alternative 
activities. Elsmore (1994) stated, "In most studies [using the SYNWORK task], six 15-min sessions are sufficient to achieve near-maximal performance" (p. 423). The experimenter remained in the room during both training sessions to answer questions. Participants were paid $\$ 5.00$ for attending each of the training sessions.

General procedures for the experimental sessions. Before each session, the experimenter reminded participants of the pay contingencies that were in effect for that day. The experimenter also told them that they could take breaks from the experimental task whenever they wanted to, and that points would not be deducted from their scores if they did so. The alternative tasks were available to participants throughout the session. The experimenter also explained that twice during the session, she would prompt them to take 10-min breaks to make sure that they did not get too tired, but that they were free to continue working, if they preferred. The experimenter then started the SYNWORK task and left the room, returning twice to prompt the participants to take breaks. SYNWORK automatically terminated the session after 90-min, at which point the experimenter returned to the room.

During all four phases, participants were paid in cash immediately after their last session of each week. As indicated earlier, most participants attended three sessions per week. If an experimental phase was completed before that session, they were paid at the end of that phase and the next pay occurred after their last session of the week.

Phase 1: Individual incentives without end-of-session feedback. Participants were told at the beginning of each session that they would earn $\$ .10$ for every 100 points earned on the SYNWORK task. When SYNWORK terminated the session after 90 min, the message "Session Over" appeared on the computer screen.

Phase 2: Individual incentives with end-of-session feedback. At the beginning of this phase, participants were told that they would now receive feedback about the number of points they earned at the end of the session. As in the previous phase, participants were reminded at the beginning of each session that they would earn $\$ .10$ for every 100 points earned. When SYNWORK terminated the session, the total number of points earned was displayed on the computer screen.

Phase 3. Individual incentives without end-of-session feedback. The end-of-session feedback was withdrawn and the conditions described in Phase 1 were re-implemented. At the beginning of this phase, participants were told that the computer would no longer display the number of points they had earned at the end of the session. 
Phase 4: Hourly pay with end-of-session feedback. During the final phase, participants were told that the computer would again display the number of points they had earned at the end of the session; however, the payment system would be more similar to the way that most organizations pay their employees, an hourly wage. They were told that they would be paid $\$ 7.50$ for the session if they earned a minimum of 4,000 points, but would not receive any pay if they earned fewer than 4,000 points.

\section{RESULTS}

\section{Points Earned}

Figures 1,2,3, and 4 display the total number of points earned per session by each participant. The point scores for each participant for each session are also provided in the Appendix.

The performance of Participant 1 was not stable when Phase 2 (incentives with feedback) was introduced and trended upward across the first two incentive phases. For the remaining six participants, performance increased from the first incentive only phase to the incentive with feedback phase. The increases for these six participants ranged from 298 points to 1,709 points, with a mean increase of 1,020 points. Performance stabilized or continued to trend upward during the incentive only reversal phase for six of the seven participants, whereas, Participant 6's performance decreased during this reversal phase. Furthermore, performance was higher in all of the incentive phases (A, B, and A) than it was in the base pay with feedback phase (Phase C) for six of the seven participants. The exception was again Participant 6, whose performance was slightly higher in the base pay phase than it was in the incentive only phases.

\section{Percentage of Correct Responses}

Table 1 displays the average percentage of correct responses for each participant for each phase. The percentage correct was high (over $89.9 \%$ ) for all participants across all phases. For six participants, accuracy was stable across all phases, varying by less than 1.5 percent. The exception was Participant 5, whose accuracy score was approximately $10 \%$ lower in the base pay with feedback condition than in the incentive 
Research Articles

81

FIGURE 1. Number of Points Earned per Session by Participants 1 and 2
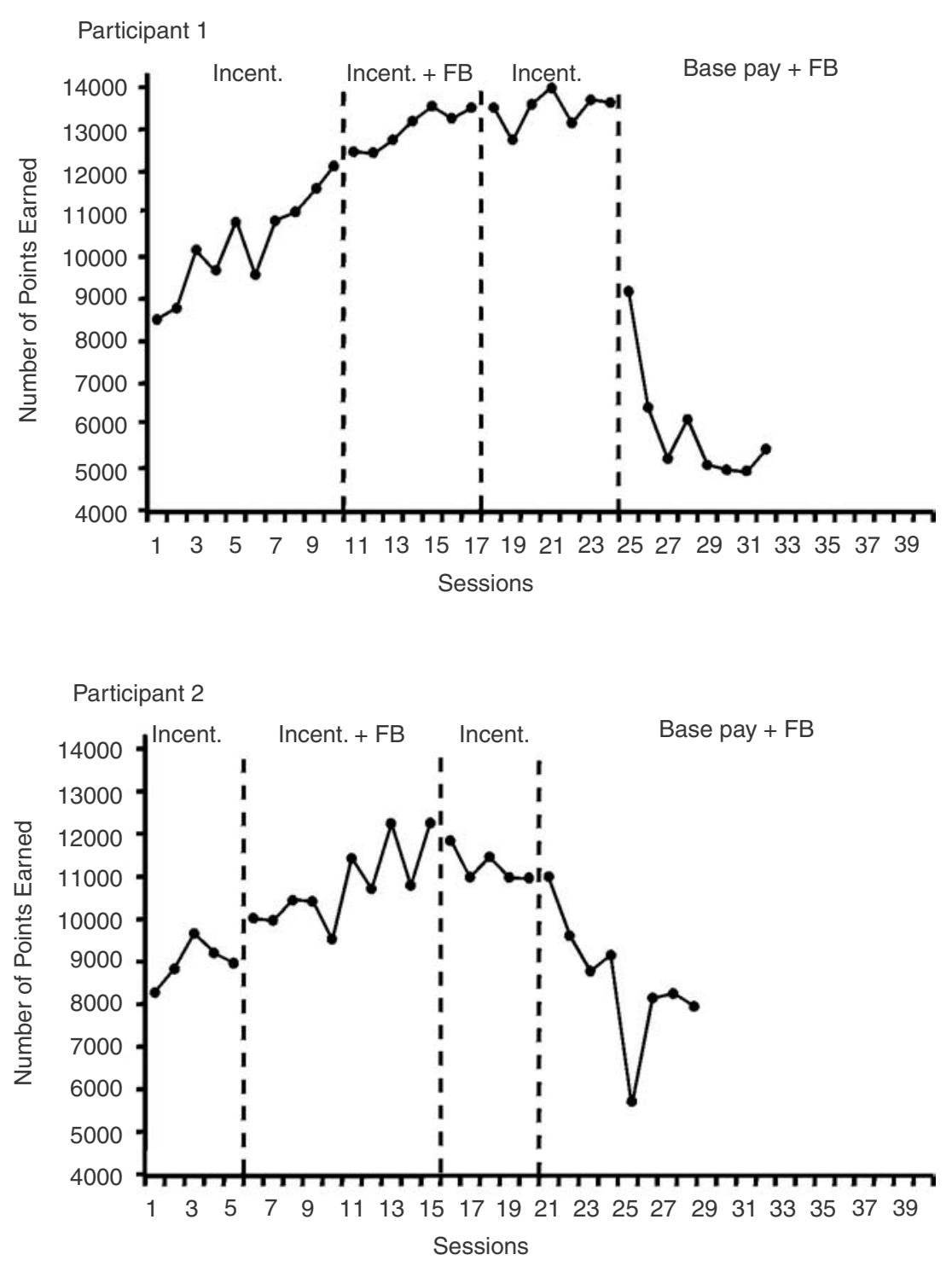
82 JOURNAL OF ORGANIZATIONAL BEHAVIOR MANAGEMENT

FIGURE 2. Number of Points Earned per Session by Participants 3 and 4
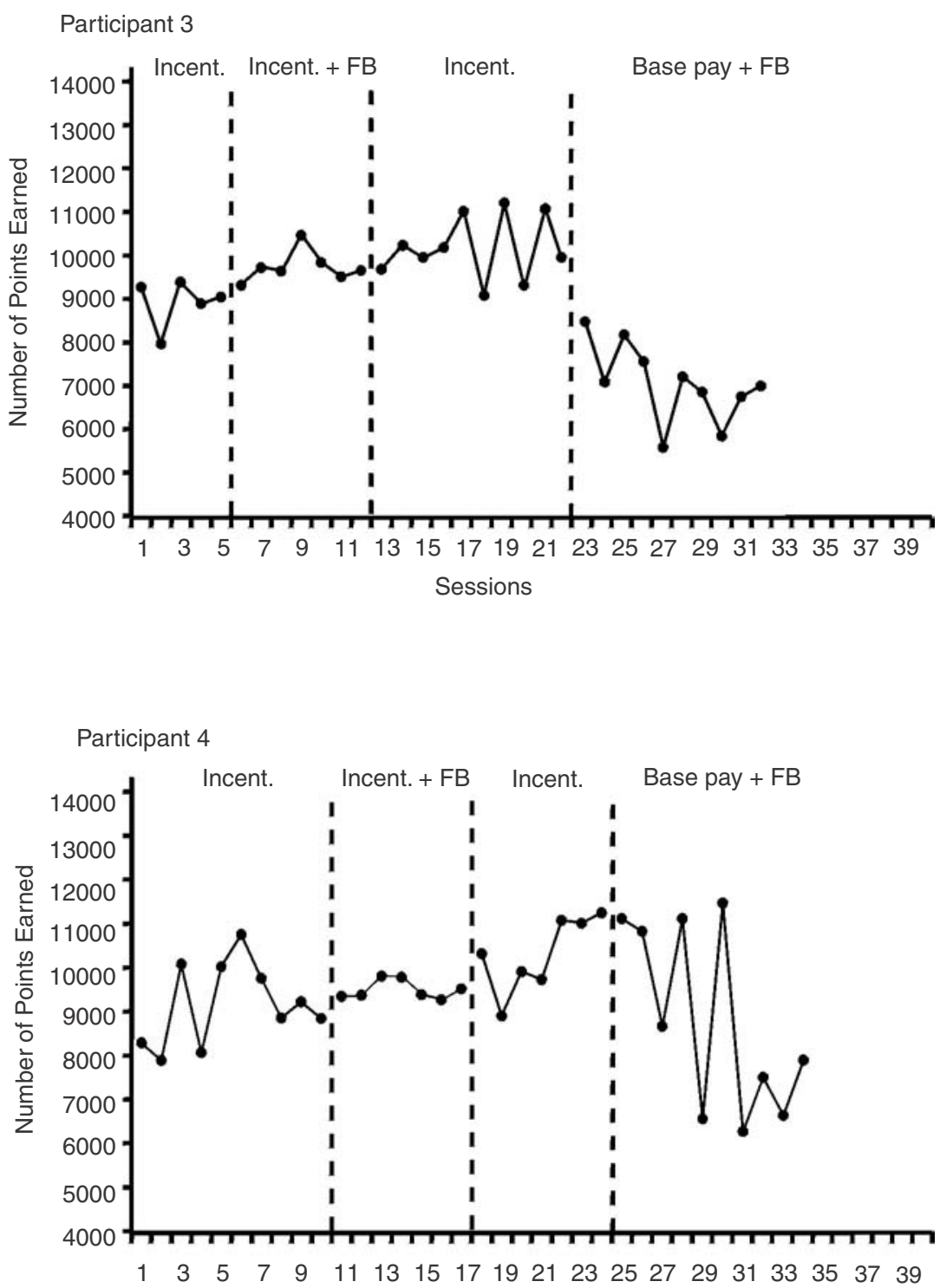
Sessions 
FIGURE 3. Number of Points Earned per Session by Participants 5 and 6
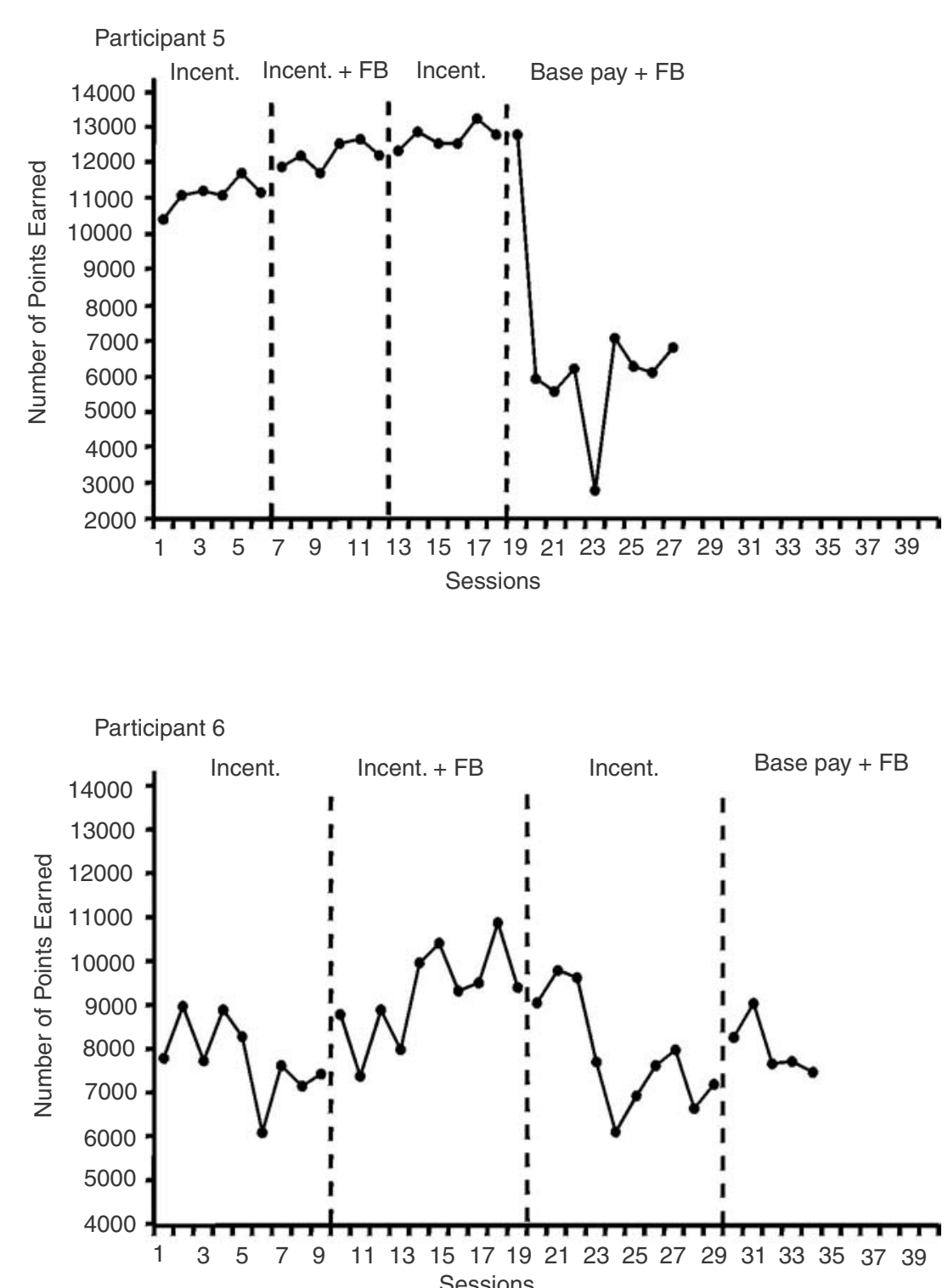
FIGURE 4. Number of Points Earned per Session by Participant 7

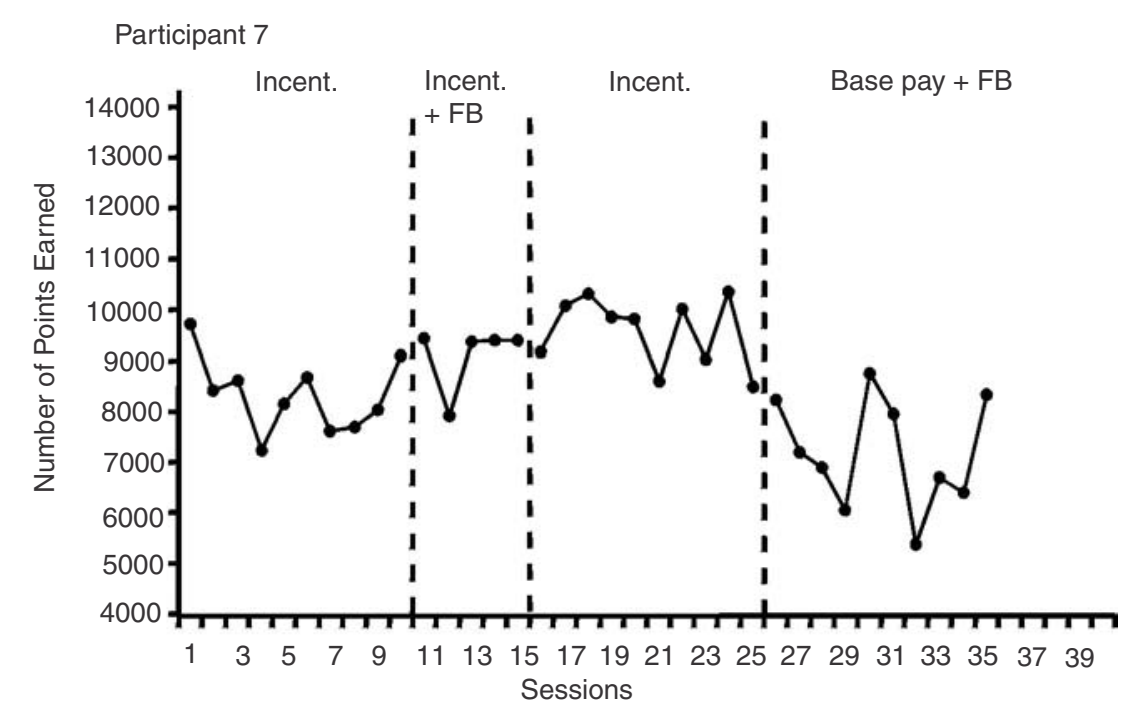

TABLE 1. Average Percentage of Correct Responses by Participant and Phase

\begin{tabular}{ccccc}
\hline Participant \# & $\begin{array}{c}\text { Individual } \\
\text { Incentives }\end{array}$ & $\begin{array}{c}\text { Individual+ } \\
\text { Feedback }\end{array}$ & $\begin{array}{c}\text { Individual } \\
\text { Incentives }\end{array}$ & $\begin{array}{c}\text { Base-pay+ } \\
\text { Feedback }\end{array}$ \\
\hline 1 & $98.7 \%$ & $98.7 \%$ & $99.0 \%$ & $98.5 \%$ \\
2 & $98.2 \%$ & $99.4 \%$ & $99.1 \%$ & $98.7 \%$ \\
3 & $98.4 \%$ & $99.1 \%$ & $99.0 \%$ & $98.9 \%$ \\
4 & $98.4 \%$ & $98.9 \%$ & $98.9 \%$ & $98.7 \%$ \\
5 & $98.7 \%$ & $99.5 \%$ & $99.5 \%$ & $89.9 \%$ \\
6 & $96.4 \%$ & $96.4 \%$ & $95.6 \%$ & $96.6 \%$ \\
7 & $99.3 \%$ & $99.2 \%$ & $99.3 \%$ & $98.6 \%$ \\
\hline
\end{tabular}


conditions. These data indicate that the monetary incentives did not decrease the quality of performance in comparison to base pay only.

\section{DISCUSSION}

Previous studies have generally found performance to be comparable under different ratio schedules of incentive delivery, percentages of incentive pay to base pay and total pay, and per piece incentives (Bucklin \& Dickinson, 2001). Feedback has been a component of these incentive systems and may have sustained performance under the various arrangements. The present study examined a $100 \%$ individual monetary incentive system with and without feedback to determine whether feedback added to the effects of the incentives and thus could account for the results of the previous studies.

\section{Incentive Only versus Incentive with Feedback}

The comparison of performance under incentive only and incentive with feedback for six of the seven participants suggests that feedback did enhance the effects of the incentives. The exception was Participant 1 , whose performance trended upward across the incentive phases. Interventions were staggered in time across the participants because participants attended a different number of sessions each week and completed a different number of sessions during the first phase of the study. The performance of the individual participants did not change until feedback was provided, lending credibility to the interpretation that feedback enhanced the effectiveness of the incentives. However, because performance did not reverse for six of the seven participations, these results must be viewed cautiously. There are, nonetheless, plausible explanations for why performance failed to reverse. The first relates to the larger incentives that resulted from increased performance when feedback was added. As suggested by Balcazar et al. (1985/86), the feedback may have functioned as discriminative stimuli because of generalization from some history of reinforcement. As such, the feedback may have evoked new and more effective forms of behavior that increased performance and led to additional incentives. Contact with these larger incentives may have maintained or increased performance, and the behaviors responsible for it, after the feedback was withdrawn.

It is also possible that environmental changes (e.g., response-produced stimuli) initiated by the feedback could not be removed. Al- 
though the SYNWORK task was used in the current study because of its complexity (to prevent performers from keeping track of their point scores during the session), anecdotal reports indicated that feedback made participants aware of performance variables such as the amount of time spent on task, overall speed of responding, and amount of time allocated to the various sub-tasks. A similar suggestion was made by Smoot and Duncan (1997) when they discussed potential reasons for their failure to find supplemental effects of feedback. Because their study removed feedback in the final condition, Smoot and Duncan stated, "the effects of the official feedback in the incentive with feedback condition may have carried over, as self-administered/unofficial feedback, to the incentive without feedback condition" (p. 36). Similarly, in the current study, because response-produced stimuli and/or stimuli associated with time allocation to the work tasks were correlated with more money, they may have taken on the function of feedback as either discriminative stimuli or conditioned reinforcers, sustaining performance once the feedback was removed.

To summarize the preceding analyses, it may be that when higher levels of performance are achieved and rewarded by more money, performance will persist even when feedback is removed; that is, performance may come under control of the additional monetary incentives and response-produced stimuli correlated with the additional incentives. If these analyses are correct, then a within-subject reversal design is not an appropriate design to use in this research. Hence, future researchers should use a different design. A multiple-baseline across subjects design wherein monetary incentives are implemented alone and then in combination with feedback, with the addition of feedback staggered in time across participants, would prevent any potential confound due to the presentation and later withdrawal of the "formal" feedback. A between-group design would also prevent such confounds. Additionally, because individual monetary incentive systems are usually implemented within units or departments with the goal of maximizing group performance by improving the performance of the greatest number of inperformance by improving the performance of the greatest number of
dividuals, the group may be the most appropriate level of analysis.

Before researchers select an experimental design to pursue this work, we encourage them to consult an excellent article by Komaki and Goltz (2001) that examines how to match the experimental design with the experimental question in order to insure the scientific merit of the study as well as the integrity of the data collected. Their critique, which focuses on interventions in organizational settings, compares between-group and within-subject experimental designs, reviews different types of be- 
tween-group and within-subject designs, advises when each is appropriate, discusses problems with their uses, and suggests how to avoid these problems. Both experienced and new researchers will find the article beneficial.

Finally, it is possible that the length of the current sessions and/or the length of the study impacted the results. This concern has been discussed in other incentive research (e.g., Honeywell et al., 2002; Smoot \& Duncan, 1997). The relatively short sessions (90 min) and the length of participation may have produced different results than would have been found in a more realistic employment setting. The possibility that session length influenced the results, however, is diminished when previous studies are considered. The length of sessions in previous studies has varied considerably, yet the results of the studies have been consistent. For example, in studies that have examined the percentage of incentive pay to base pay or total pay, sessions have been $45 \mathrm{~min}$ (Frisch \& Dickinson, 1990), 4 hours (Dickinson \& Gillette, 1993) and, although it is awkward to talk about session length in an applied study, an 8-hour work day (LaMere et al., 1996). Nonetheless, session length, combined with the relatively short length of the study, may have influenced the results.

Phase length may well have contributed to the reversal failure: If the reversal condition had been carried out for longer than 5 to 10 sessions, performance may have decreased to initial levels. No prior data exist to support or refute this possibility.

\section{Base Pay with Feedback versus Incentives}

\section{With and Without Feedback}

All participants displayed higher performance when feedback was combined with incentives than when feedback was combined with hourly pay, suggesting that monetary incentives do enhance the effects of feedback. Moreover, for six of the seven participants (Participants 1 , $2,3,4,5$ and 7 ), performance was considerably higher during the incentive without feedback condition than during the base pay plus feedback condition. These results support those of previous studies of individual incentives, which found higher performance levels under individual incentives than under hourly pay (e.g., Frisch \& Dickinson, 1990; Gaetani et al., 1985; George \& Hopkins, 1989; LaMere et al., 1996; London \& Oldham, 1977; Pritchard et al., 1980; Riedel et al., 1988; Smoot \& Duncan, 1997; Wagner \& Bailey, 1997). In these studies, feedback was provided along with individual incentives and base pay. Thus, the re- 
sults support Balcazar et al.'s (1985/86) and Alvero et al.'s contention that feedback is more effective when combined with other, more functional reinforcers, such as monetary incentives.

Results relating to the comparison of incentives only with base pay with feedback are unique to the current study. In prior studies, feedback was a component of both the incentive systems and the hourly pay systems. The base pay with feedback condition was primarily included to demonstrate that the monetary incentives controlled the work performance of participants; without such a demonstration, a valid comparison of the effects of the two individual monetary incentive systems would not be possible. Nonetheless, the current analysis allowed for the assessment of performance differences between incentives without feedback and hourly pay with feedback. The results indicate that individual incentives alone are more effective than base pay with feedback. The precipitous decrease in performance during the base pay with feedback phase for all but one participant (Participant 6), however, may have resulted, at least in part, from the fact that this condition occurred at the end of the study. Additional research is needed to determine whether such differences are reproducible, using experimental procedures that are better controlled. It should also be noted that during the base pay with feedback condition, most participants performed well above the 4,000-point minimum, suggesting that the feedback did influence performance under this straight-wage condition.

In the current study, the delay between performance and the feedback was short compared to the delays that typically occur in actual employment settings. If the performance of participants during the hourly pay with feedback condition is representative of the comparatively low levels of performance that indeed occur, the delayed feedback in applied settings may be even less effective. Future researchers are encouraged to conduct studies that more closely approximate the delayed feedback conditions that exist in actual work settings. Studies that examine parametrically different delays across different pay systems would be particularly beneficial.

\section{A Methodological Concern: The Stability Criterion}

The stability criterion for changing phases was violated a number of times. Because of financial constraints, phases were changed after 10 sessions even if the performance of a participant did not meet the criterion. Phase 2 was introduced before the performances of Participants 1 and 7 were stable, Phase 3 was introduced before the performances of 
Participants 2 and 6 were stable, and Phase 4 was introduced before the performances of Participants 3 and 6 were stable. The early introduction of Phase 4 did not affect the interpretation of the data because the performance of most of the participants changed appreciably during this phase. On the other hand, the early introduction of Phase 2 for Participants 1 and 7, made it difficult to interpret the results and, therefore, represent a weakness in the study.

For the benefit of future researchers who may wish to replicate this study, it should be noted that there was a problem with the stability criterion. If researchers were to adopt the same criterion, they may not be able to achieve "stable" baselines. The criterion required that the total point scores of the participant be within a range of 750 points for three consecutive sessions. The criterion was based on the performance of participants in a previous study that used SYNWORK as the experimental task (Honeywell et al., 2002). However, under similar experimental conditions (e.g., individual monetary incentives with end-ofsession feedback and hourly pay with end-of-session feedback), the point scores of the participants in the current study varied considerably more across the participants than did the point scores of the participants in that prior study. Because the criterion was based on a fixed number of points, it was proportionately more lenient when point scores were low than when they were high. When performance varies as much as it did in this study (both across participants and across conditions for the same participant), a criterion based on a percentage is probably more appropriate.

\section{SUMMARY}

This study is primarily important because, although not definitive, the results suggest that feedback does enhance the effects of monetary incentives. Organizations should be alerted to that possibility and, in addition, future studies should examine the effects of various incentive pay arrangements with and without feedback to determine whether feedback eliminates performance differences that may otherwise occur. The results are also of benefit to future researchers because they suggest that, when combined with individual monetary incentives, the effects of feedback may not be reversible, and hence other research designs should be adopted. Because previous attempts to study incentives with and without feedback were flawed (e.g., Agnew et al., 1992; Smoot \& Duncan, 1997), no prior relevant data were available. 
Finally, this study was unique in that it compared the effects of individual monetary incentives alone with the effects of base pay with feedback. The results suggest that individual monetary incentives alone result in higher performance than base pay with feedback.

\section{REFERENCES}

Adam, E. E., Jr. (1972). An analysis of changes in performance quality with operant conditioning procedures. Journal of Applied Psychology, 56, 480-486.

Agnew, J. L., Dickinson, A. M., Acker, L. E., Cronin, K. M., \& Goldwater, B. C. (1992, May) The supplemental effects of feedback on work performance under a monetary incentive system. Paper presented at the meeting of the Association for Behavior Analysis International: San Francisco, CA.

Agnew, J. L., \& Redmon, W. K. (1992). Contingency specifying stimuli: The role of Agnew, J." L., \& Redmon, W. K. (1992). Contingency specifying stimuli: The role of
"rules" in organizational behavior management. Journal of Organizational Behav"rules" in organizational behavior
ior Management, 12(2), 67-76.

Alvero, A. M., Bucklin, B. R., \& Austin, J. (2001). An objective review of the effectiveness and essential characteristics of performance feedback in organizational settings (1985-1998). Journal of Organizational Behavior Management, 21(1), 3-29. Balcazar, F., E., Hopkins, B., \& Suarez, Y. (1985/86). A critical objective review of performance feedback. Journal of Organizational Behavior Management, 7(3/4), 65-89.

Balcazar, F. E., Shupert, M. K., Daniels, A. C., Mawhinney, T. C., \& Hopkins, B. L. (1989). An objective review and analysis of ten years of publication in the Journal of Organizational Behavior Management. Journal of Organizational Behavior of Organizational Behavio

Berger, C. J., Cummings, L. L., Heneman, H. G. (1975). Expectancy theory and operant conditioning predictions of performance under variable ratio and continuous schedules of reinforcement. Organizational Behavior and Human Performance, $14,227-243$

Bucklin, B. R., Alvero, A. M., Dickinson, A. M., Austin, J., \& Jackson, A. K. (2000) Industrial-Organizational Psychology and Organizational Behavior Management: An objective comparison. Journal of Organizational Behavior Management, 20(2), An objecti $27-75$.
.

Bucklin, B. R., \& Dickinson, A. M. (2001). Individual monetary incentives: A review of different types of arrangements between performance and pay. Journal of Organizational Behavior Management, 21(3), 45-137.

Buyniski, T. R. (1995, May-June). "Feedback pay": Using compensation as a business management tool. Compensation and Benefits Review, pp. 62-70.

Dickinson, A. M., \& Gillette, K. L. (1993). A comparison of the effects of two individual monetary incentive systems on productivity: Piece rate pay versus base pay plus monetary incentives. Journal of Organizational Behavior Management, 14(1), $2-82$. 
Dickinson, A. M., \& Poling, A. D. (1996). Schedules of monetary reinforcement in Organizational Behavior Management: Latham and Huber (1992) Revisited. Journal of Organizational Behavior Management, 16(1), 71-91.

Dierks, W., \& McNally, K. (1987). Incentives you can bank on. Personnel Administrator, 32, 61-65

Duncan, P. K., \& Bruwelheide, L. R. (1985/86). Feedback: Use and possible behavioral functions. Journal of Organizational Behavior Management, 7(3/4), 91-114.

Duncan, P. K., \& Smoot, D. T. (2001). Pay for performance. In C. M. Johnson, W. K. Redmon, \& T. C. Mawhinney (Eds.), Handbook of organizational performance:
Rencan, P. K., \& Smoot, D. T. (2001). Pay for performance. In C. M. Johnson, W. K. Redmon, \& T. C. Mawhinney (Eds.), Handbook of organizational performance:
Behavior analysis and management (pp. 255-276). New York: The Haworth Press, Inc. Behavior analysis and management (pp. 255-276). New York: The Haworth Press, Inc.
Elsmore, T. F. (1994). SYNWORK 1: A PC-based tool for assessment of performance in a simulated work environment. Behavior Research Methods, Instruments, \&
inter in a simulated work environ
Computers, 26, 421-426.

Elsmore, T. F., Naitoh, P., \& Linnville, S. (1992). Performance assessment in sustained operations using a computer-based synthetic work task (Office of Naval Technology Report No. 92-30).

Fairbank, J. A., \& Prue, D. M. (1982). Developing performance feedback systems. In L. W. Frederiksen (Ed.), Handbook of Organizational Behavior Management (pp. 281-299). New York: John Wiley.

Fitts, P. M. (1966). Cognitive aspects of information processing: III. Set for speed vs. accuracy. Journal of Experimental Psychology, 71, 849-857.

Frisch, C. J., \& Dickinson, A. M. (1990). Work productivity as a function of the per-

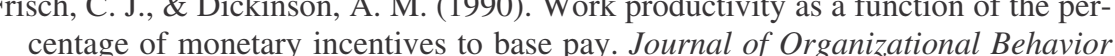
centage of monetary incen

Gaetani, J. J., Hoxeng, D. D., \& Austin, J. T. (1985). Engineering compensation systems: Effects of commissioned versus wage payment. Journal of Organizational Behavior Management, 7(1/2), 51-63.

George J. T., \& Hopkins, B. L. (1989). Multiple effects of performance-contingent pay for waitpersons. Journal of Applied Behavior Analysis, 22, 131-141.

Hantula, D. A. (2001). Schedules of reinforcement in organizational performance, 1971-1994: Application, analysis and synthesis. In C. M. Johnson, W. K. Redmon, \& T. C. Mawhinney (Eds.), Handbook of organizational performance: Behavior analysis and management (pp. 139-166). New York: The Haworth Press, Inc.

Honeywell, J. A., McGee, H. M., Culig, K. M., \& Dickinson, A. M. (2002). Different effects of individul and smell group incentives on high performance The Behavior effects of individual and small group incentives on high performance. The Behavior
Analyst Today, 3(1), 88-103. Analyst Today, 3(1), 88-103.

Akins, G. D., Gupta, N., Mitra, A., \& Shaw, J. D. (1998). Are financial incentives related to performance? A meta-analytic review of empirical research. Journal of Applied Psychology, 83, 777-787

Komaki, J. L., \& Goltz, S. M. (2001). Within-group research designs: Going beyond program evaluation questions. In C. M. Johnson, W. K. Redmon, \& T. C. Mawhinney (Eds.), Handbook of organizational performance: Behavior analysis and management (pp. 81-137). New York: The Haworth Press, Inc.

LaMere, J. M., Dickinson, A. M., Henry, G., Henry, M., \& Poling, A. D. (1996). Effects of a multicomponent monetary incentive program on the performance of truck drivers. Behavior Modification, 20, 385-405. 
Latham, G. P., \& Dossett, D. L. (1978). Designing incentive plans for unionized employees: A comparison of continuous and variable-ratio reinforcement schedules Personnel Psychology, 31, 47-61.

London, M., \& Oldham, G. R. (1977). A comparison of group and individual incentive plans. Academy of Management Journal, 20, 34-41

Matthews, G. A., \& Dickinson, A. M. (2000). Effects of alternative activities on productivity under different percentages of incentive pay. Journal of Organizational Behavior Management, 20(1), 3-27.

Mawhinney, T. C. (1975). Operant terms and concepts in the description of individual work behavior: Some problems of interpretation, application and evaluation. Journal of Applied Psychology, 60, 704-712.

Mawhinney, T. C. (1982). Maximizing versus matching in people versus pigeons. Psychological Reports, 50, 267-281.

Mawhinney, T. C. (1984). Philosophical and ethical aspects of organizational behavior management: Some evaluative feedback. Journal of Organizational Behavior Management, 6(1), 5-31

Mawhinney, T. C., \& Mawhinney, R. R. (1982). Operant terms and concepts applied to industry. In R. M. O'Brien, A. M. Dickinson, \& M. P. Rosow (Eds.), Industrial behavior modification: A management handbook (pp. 115-139). New York: The Haworth Press, Inc.

Michael, J. (1982). Distinguishing between discriminative and motivational functions of stimuli. Journal of the Experimental Analysis of Behavior, 37, 149-155.

of stimuli. Journal of the Experimental Analysis of Behavior, 37, 149-155.
Nolan, T. V., Jarema, K. A., \& Austin, J. (1999). An objective review of the journal of Nolan, T. V., Jarema, K. A., \& Austin, J. (1999). An objective review of the journal of
organizational behavior management: 1987-1997. Journal of Organizational Behavior Management, 19(3), 83-114

Oah, S., \& Dickinson, A. M. (1992). A comparison of the effects of a linear and an exponential performance pay function on work productivity. Journal of Organizational Behavior Management, 12(1), 85-115.

Parsons, H. M. (1974). What happened at Hawthorne? Science, 183, 922-932.

Parsons, H. M. (1974). What happened at Hawthorne? Science, 183, 922-932.
Parsons, H. M. (1978). What caused the Hawthorne effect? A scientific detective story. Administration and Society, 10, 259-283.

Parsons, H. M. (1992). Hawthorne: An early OBM experiment. Journal of Organizational Behavior Management, 12(1), 27-43.

Peterson, N. (1982). Feedback is not a new principle of behavior. The Behavior Analyst, 5, 101-102.

Pritchard, R. D., Hollenback, J., \& DeLeo, P. J. (1980). The effects of continuous and partial schedules of reinforcement on effort, performance and satisfaction. Organizational Behavior and Human Performance, 25, 336-353.

Pritchard, R. D., Leonard, D. W., Von Bergen, C. W., \& Kirk, R. J. (1976). The effects of varying schedules of reinforcement on human task performance. Organizational Behavior and Human Performance, 16, 205-230.

Riedel, J. A., Nebecker, D. M., \& Cooper, B. L. (1988). The influence of monetary incentives on goal choice, goal commitment and task performance. Organizational Behavior and Human Decision Processes, 42, 155-180. 
Saari, L. M., \& Latham, G. P. (1982). Employee Reactions to Continuous and Variable Ratio Reinforcement Schedules Involving a Monetary Incentive. Journal of Applied Psychology, 67, 506-508

Smoot, D. A., \& Duncan, P. K. (1997). The search for optimum individual monetary incentive pay system: A comparison of the effects of flat pay and linear and non-linear pay systems on worker productivity. Journal of Organizational Behavior Management, 17(2), 5-75.

Stolovich, H. D. Clark, R. E. \& Condly, S. J. (2002). Incentives, motivation and workplace performance: Research \& best practices. Silver Spring, MD: International Society for Performance Improvement and SITE Foundation.

Wagner, K. I., \& Bailey, J. S. (1997). The effects of a monetary incentive system on work performance of mental health counselors. Performance Improvement Quar-
wantem work performance of mental health counselors. Performance Improvement Quar-
terly, 11, 64-78. terly, 11, 64-78.

ukl, G. A., \& Latham, G. P. (1975). Consequences of reinforcement schedules and incentive magnitudes for employee performance: Problems encountered in an industrial setting. Journal of Applied Psychology, 60, 294-298.

Yukl, G. A., Latham, G. P., \& Pursell, E. D. (1976). The effectiveness of performance incentives under continuous and variable ratio schedules of reinforcement. Personnel Psychology, 29, 221-231.

Yukl, G. A., Wexley, K. N., \& Seymore, J. D. (1972). Effectiveness of pay incentives under variable ratio and continuous reinforcement schedules. Journal of Applied Psychology, 56, 19-23. 
APPENDIX

Number of Points Earned by Each Participant in Each Session

\begin{tabular}{crrrrrrr} 
Session & P1 & \multicolumn{1}{c}{ P2 } & \multicolumn{1}{c}{ P3 } & \multicolumn{1}{c}{ P4 } & P5 & P6 & \multicolumn{1}{c}{ P7 } \\
\hline 1 & 8461 & 8106 & 9096 & 8279 & 10354 & 7743 & 9677 \\
2 & 8816 & 8652 & 7822 & 7850 & 11032 & 8925 & 8379 \\
3 & 10183 & 9452 & 9231 & 9959 & 11187 & 7698 & 8565 \\
4 & 9636 & 9034 & 8762 & 8032 & 11071 & 8861 & 7222 \\
5 & 10885 & 8751 & 8912 & 9874 & 11690 & 8228 & 8097 \\
6 & 9531 & 9770 & 9132 & 10623 & 11119 & 6072 & 8658 \\
7 & 10805 & 9740 & 9542 & 9650 & 11860 & 7598 & 7571 \\
8 & 11066 & 10168 & 9467 & 8773 & 12158 & 7130 & 7658 \\
9 & 11576 & 10163 & 10237 & 9170 & 11654 & 7431 & 7996 \\
10 & 12116 & 9310 & 9641 & 8750 & 12493 & 8742 & 9062 \\
11 & 12442 & 11137 & 9338 & 9266 & 12617 & 7346 & 9410 \\
12 & 12412 & 10421 & 9467 & 9281 & 12164 & 8859 & 7886 \\
13 & 12728 & 11927 & 9511 & 9680 & 12283 & 7965 & 9327 \\
14 & 13154 & 10524 & 10071 & 9669 & 12826 & 9953 & 9358 \\
15 & 13554 & 11923 & 9778 & 9263 & 12495 & 10353 & 9360 \\
16 & 13251 & 11550 & 9975 & 9182 & 12525 & 9305 & 9131 \\
17 & 13500 & 10711 & 10822 & 9416 & 13191 & 9454 & 10050 \\
18 & 13513 & 11173 & 8929 & 10187 & 12750 & 10849 & 10253 \\
19 & 12728 & 10717 & 11012 & 8832 & 12753 & 9342 & 9815 \\
20 & 13630 & 10715 & 9148 & 9830 & 5914 & 8987 & 9768 \\
21 & 13956 & 10782 & 10860 & 9628 & 5511 & 9770 & 8557 \\
22 & 13128 & 10743 & 9767 & 10892 & 6184 & 9559 & 9961 \\
23 & 13655 & 9374 & 8337 & 10839 & 2760 & 7682 & 8966 \\
24 & 13617 & 8591 & 6953 & 11091 & 7031 & 6080 & 10309 \\
25 & 9198 & 8951 & 8038 & 10934 & 6244 & 6929 & 8440 \\
26 & 6417 & 5621 & 7442 & 10714 & 6084 & 7589 & 8200 \\
27 & 5188 & 7977 & 5488 & 8620 & 6766 & 7950 & 7159 \\
28 & 6161 & 8089 & 7095 & 10947 & & 6639 & 6861 \\
29 & 5070 & 7770 & 6746 & 6632 & & 7181 & 6045 \\
30 & 4952 & & 5761 & 11306 & & 8250 & 8705 \\
31 & 4895 & & 6640 & 6332 & & 9005 & 7909 \\
32 & 5479 & & 6903 & 7504 & & 7621 & 5362 \\
33 & & & & 6668 & & 7709 & 6686 \\
34 & & & & 7895 & & 7459 & 6371 \\
35 & & & & & & & 8295
\end{tabular}

